\title{
NARRATIVAS DE UNANIMIDADE E DIÁLOGO EM PROTOCOLOS SINODAIS E HAGIOGRAFIAS TARDO-ANTIGAS ${ }^{1}$
}

\author{
Luise MARion FrenKeL* \\ Universidade de São Paulo
}

\begin{abstract}
Resumo. Analiso cenas de convocação nas cartas e protocolos circulados pela facção majoritária dos líderes cristãos reunidos em Éfeso em 431 d.C. atentando sobretudo à obliquidade das narrativas que contêm e aos aspectos verbais e não verbais a que se referem. Contrasto-as com as acusações e sanções mútuas, mencionadas nas cartas e panfletos dos representantes imperiais e dos líderes das facções litigantes, que corroboram ou enfraquecem a representação de consenso por meio de documentos escritos. Problematizo assim a narrativa em que são cumpridas as instruções imperiais de realização de discussões sobre assuntos de fé cristã baseadas no precedente de Nicéia, em unanimidade e diálogo e que obteve sanção imperial das decisões. Este estudo literário e histórico da função argumentativa dos protocolos sinodais tardo-antigos corrobora que, também nos exemplos em que há uma documentação mais ampla dos encontros de lideranças eclesiásticas, a representação dos eventos permanece parcial e que eles não são típicos de um fenômeno amplo. Por fim, a análise da credibilidade dos relatos das demonstrações populares e monásticas em Constantinopla, atentando aos aspectos não-verbais neles realçados, contribui ao estudo da circulação inicial de atas sinodais.
\end{abstract}

Palavras-chave. Oralidade; oratória tardo-antiga; epistolografia; circulação de protocolos sinodais; administração imperial romana.

D.O.I. 10.11606/issn.2358-3150.v17i1p84-96

ANALISAREI A CONSTRUÇÃo E RECEPÇÃo DE NARRATIVAS PARCIAIS EM ENcontros deliberativos tardo-antigos nas quais pode-se comparar ou contrastar discurso relatado, mensagem escrita, apresentação oral dos portadores dos escritos, e elementos do contexto e da linguagem não-verbal dos vários oradores envolvidos nas cenas. Trabalharei sobretudo com as minutas da sessão de 22 de junho de 431 em Éfeso e a narrativa nas Atas Coptas que constituem uma "Vida de Apa Vitor". São textos de dois gêneros, a

\footnotetext{
• Professora Doutora de Língua e Literatura Grega do Departamento de Letras Clássicas e Vernáculas da USP.

" Artigo recebido em 26.ago.2014 e aceito para publicação em 12.nov.2014.

${ }^{1}$ Uma versão preliminar desse trabalho foi apresentado no XIII Colóquio do CPA / III Semana de Estudos Clássicos do IEL "Linguagens e Narrativas" (Campinas, outubro de 2013), com apoio da FAPESP. NB: a abreviação ACO refere-se a Schwartz (1914ff.) seguido da indicação de "tomo fascículo/parte, página.linha".
} 
saber, as atas sinodais e as hagiografias, gêneros estes que surgiram nos primeiros séculos d.C. atendendo quer às expectativas executivas e administrativas do Império Romano, quer à matéria biográfica e encomiástica cara a cristãos de diversos setores da sociedade.

Enquanto a literatura especializada sobre hagiografias é abundante e conhece um recente florescimento, ${ }^{2}$ ainda são pouco conhecidos os estudos que analisam procedimentos conciliares como um gênero literário tardo-antigo. Textos pertencem ao gênero das atas sinodais quando contêm informações sobre encontros de líderes cristãos, que se auto-denominam sínodos, e suas decisões. Em alguns poucos casos, as atas são fictícias, pois os encontros a que se referem, embora agendados e planejados, não ocorreram. A maior parte das atas contém apenas listas de decisões e cartas sinodais. ${ }^{3}$ Os seus remetentes são os líderes reunidos e os recipientes são vários, normalmente encabeçados por uma lista de líderes que não estiveram presentes, por exemplo, aqueles de outras províncias.

Dentro desse arcabouço, uma minoria de atas contém relatos dos encontros e outros documentos, tais quais cartas de indivíduos que às vezes também descrevem os eventos. Em todas essas narrativas, nota-se uma tensão entre apresentar um registro que sustente os interesses dos autores frente à necessidade de construir uma versão verossímel, visto que foram eventos com muitas testemunhas, nem sempre favoráveis, que poderiam ter posto em cheque o valor de verdade da versão apresentada e apontado trechos forjados, como por vezes fizeram. Assim, apesar da obliquidade dos discursos contidos nestes textos tardo-antigos, aceita-se a veracidade da maior parte do relato e pensamos poder entrever paradigmas de processos de decisão coletiva no Império Romano do Oriente nas descrições das discussões, diálogos, discursos e relatos das atas sinodais. ${ }^{4}$

Tratarei da linguagem não-verbal e verbal, falada ou escrita, tanto dos oradores como dos demais envolvidos nos encontros que relatam. Analisarei a construção de uma narrativa de unanimidade e diálogo ao discutir a recepção antiga de atas sinodais no caso do Concílio de Éfeso de 431, ou melhor, das versões redigidas por cada facção, visto que todos os que foram convidados pelo imperador Teodósio II nunca se reuniram juntos. Cabe lembrar que as deposições de Nestório de Constantinopla pelos cirilianos, e de Cirilo de Alexandria e Memnon de Éfeso pelos assim chamados

\footnotetext{
${ }^{2}$ Van Uytfanghe 1993; Hatlie 2007, 9-16; Rapp 2012.

${ }^{3}$ Weckwert 2010; Chrysos 1983; Graumann 2010a. Veja Cubitt (2009) acerca das atas "fictícias" do Concílio Laterano de 649 e Price (2009) quanto a omissões e ficções nas atas do Concílio de Calcedônia. ACO II 1/1, 168-80 contém críticas à veracidade das minutas do sínodo de Éfeso em 449.

${ }^{4}$ Millar 2006, 33-4.
} 
Orientais foram decididas por questões técnicas, de natureza disciplinar, e não doutrinárias. ${ }^{5}$

\section{NARRATIVAS DE DIÁLOGO}

Na versão ciriliana, majoritária e mais difundida nos livros de história e religião modernos, há uma passagem em que um dos membros pede que se esclareça por que Nestório não está presente. ${ }^{6}$ Segue-se um relato da reação de Nestório à visita de um pequeno grupo que lhe transmitia a decisão de Cirilo de iniciar o sínodo antes da chegada de todos os bispos convidados (após semanas de espera faltavam apenas quatro dias para chegar também um grupo substancial de bispos Orientais, incluindo os mais importantes e renomeados teólogos). São as falas de quatro dos bispos que se encontraram com Nestório e nelas descrevem-se como emissários enviados pelo sínodo, enquanto a matéria relatada indica que não se caracterizaram assim no dia anterior, quando o sínodo ainda não fora instaurado. Dizem que Nestório recebeu o grupo, disse que se preciso compareceria, e os bispos que estavam com ele também afirmaram que iriam se lhes parecesse certo.? Ouvindo o relato na sessão, os cirilianos decidem convocá-lo novamente. Escolhem emissários e postergam seu encontro. Esses emissários levam uma

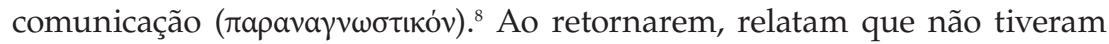
acesso a Nestório pois soldados armados impediram a sua entrada. Aguardaram, alegando que só poderiam retornar com uma resposta à comunicação, mas essa eles nunca transmitem. A resposta que recebem dos clérigos e de Florêncio, um colega de Candidiano, refere-se à descrição da comunicação que os emissários haviam dado e expressa a decisão de, quando todos os bispos chegarem, encontrarem-se com eles. ${ }^{9}$ A reação do sínodo ciriliano

\footnotetext{
${ }^{5}$ Uma reconstrução histórica sucinta e detalhada é dada em Fraisse-Coué 1995.

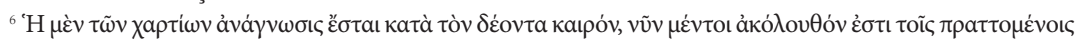

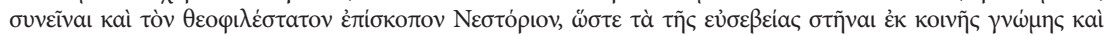

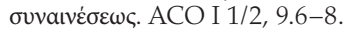

${ }^{7}$ ACO I 1/2, 9.9-30.

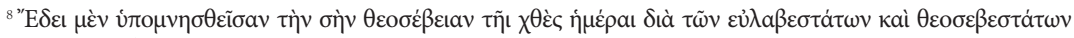

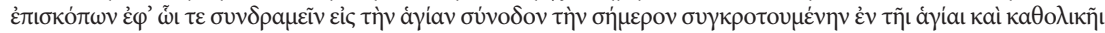

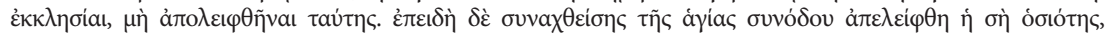

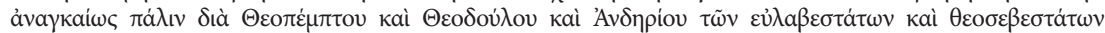

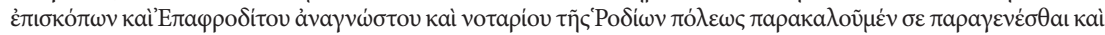

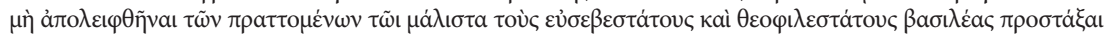

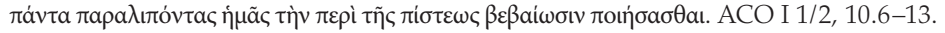

9 'A

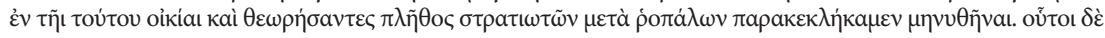


é enviar mais uma delegação, com outra comunicação, ${ }_{1}^{10}$ que ao retornar relatou que novamente soldados armados estavam na porta e impediram sua entrada. A delegação descreve os abusos verbais dos soldados contra eles, e que após uma longa espera, os soldados esclareceram que ela não receberia outras respostas. Nesse relato, apenas soldados falam com os enviados. ${ }^{11} \mathrm{Ou}$ seja, há três principais discursos que contribuem matéria para a narrativa dada nas atas. Há o discurso escrito das duas comunicações, o registro do discurso oral dos emissários na sessão e dentro deste o relato de suas falas e ações bem como da reação linguística e gestual dos demais presentes.

A maior parte da literatura especializada analisa ou a linguagem verbal cada vez mais técnica, isto é, jurídica, das comunicações de cada grupo, ${ }^{12}$ ou as questões de segurança, violência e recurso às tropas imperiais por bispos mencionadas nos discursos. ${ }^{13}$ Contudo, pouca atenção é dada à não transmissão das comunicações, pois os dois grupos enviados pelos cirilianos para convocar Nestório nunca tiveram oportunidade para

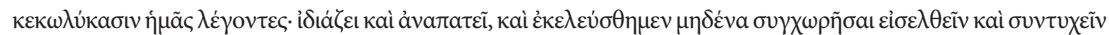

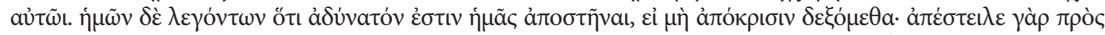

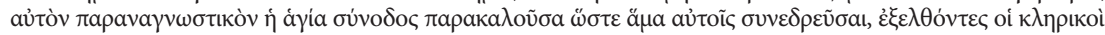

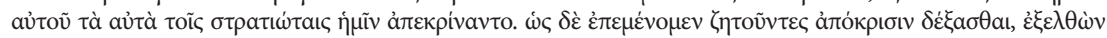

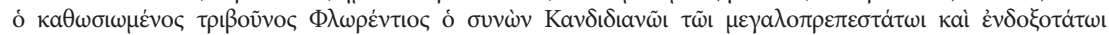

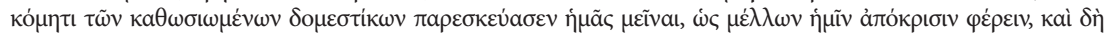

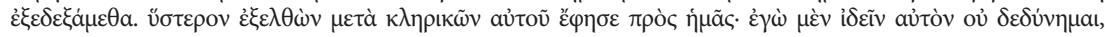

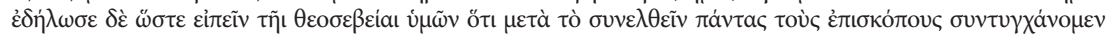

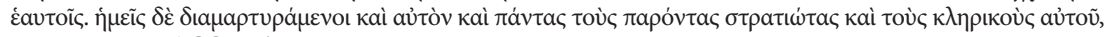

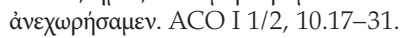

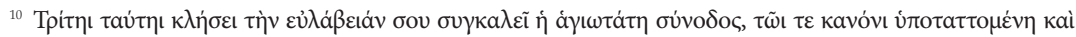

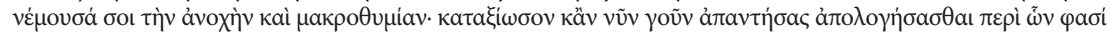

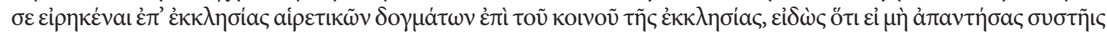

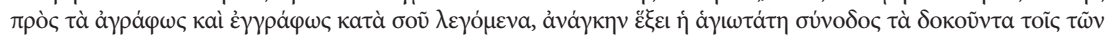

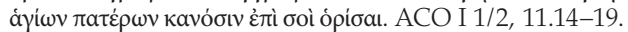

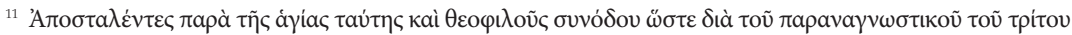

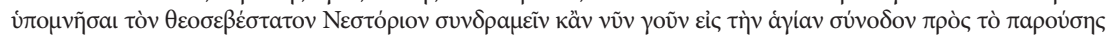

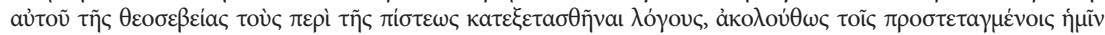

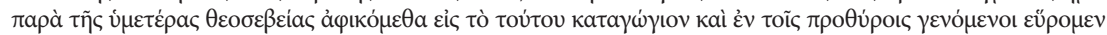

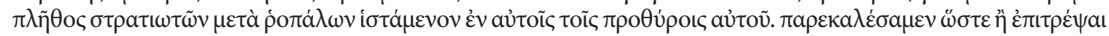

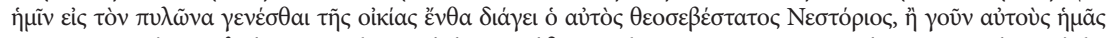

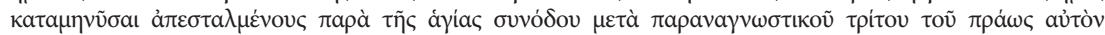

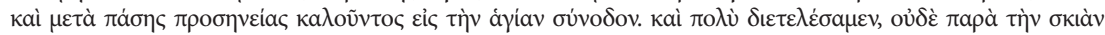

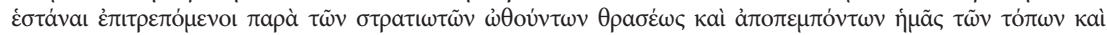

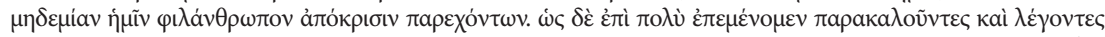

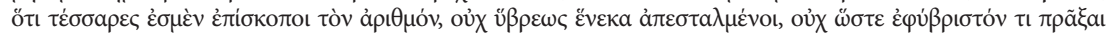

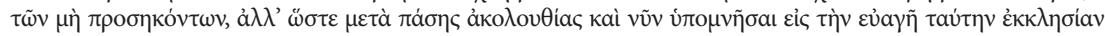

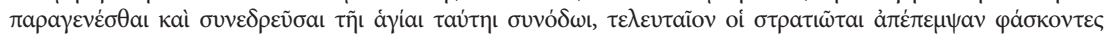

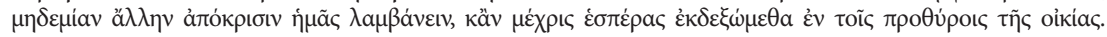

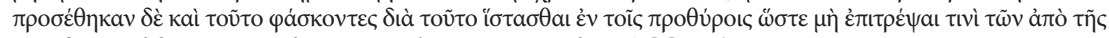

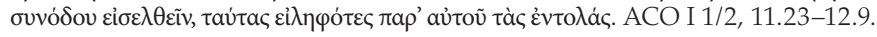

${ }^{12}$ Graumann 2002, 362-5.

${ }^{13}$ McLynn 2009, II, 15-7.

Let. Cláss., São Paulo, v. 17, n.1, p. 84-96, 2013 
apresentá-las ou entregá-las, segundo os seus testemunhos. Comparando as passagens que mencionam os relatos das delegações com o restante das minutas da sessão de 22 de junho de 431, vê-se que os redatores tinham em mãos uma versão escrita das comunicações, que copiaram dentro das minutas segundo as convenções do gênero. ${ }^{14}$ Cabe portanto averiguar a importância que as comunicações escritas tiveram nas cenas e na recepção inicial do sínodo ciriliano.

Ao exporem a razão de sua visita, os emissários mencionavam a comunicação e seu assunto. Da primeira vez, disseram que o "sagrado sínodo

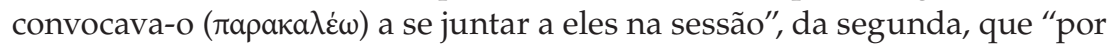
aquela terceira comunicação, o sagrado sínodo chamava-o ( $\kappa \lambda \dot{\varepsilon} \omega)$ branda-

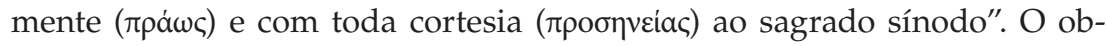
jeto físico da comunicação escrita servia de garantia para sua identificação e conferia autoridade ao portador..$^{15}$ Três aspectos merecem ser sobretudo destacados: a todo momento deixavam explícito que os cirilianos se instituíram como sagrado sínodo; que sua contagem de convites incluía a visita do dia anterior que se dera de modo muito mais informal e dialógico e

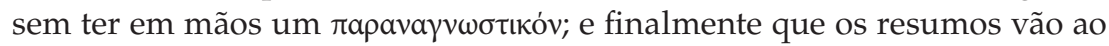
cerne das comunicações mas não refletem seus conteúdos. A descrição mais amena da terceira comunicação contrasta com o tom mais afiado do texto que portavam na ocasião e o relato do terceiro grupo de emissários é dominado pela oposição de sua atitude passiva e paciente com a agressividade e insolência dos militares, ou seja, não o discurso verbal, nem mesmo falado, mas sobretudo a linguagem não verbal caracteriza os envolvidos. ${ }^{16} \mathrm{~A}$ narração de aspectos não-verbais mostra-se decisiva para angariar a simpatia dos que ouviam os emissários bem como dos leitores das minutas, a julgar da recepção dominante dos eventos. O contraste dos aspectos não-verbais das cenas contadas pelos emissários influenciou também este público, que deixava de lado o conteúdo das comunicações e não notava que a reação de Nestório, seus companheiros e dos soldados e oficiais imperiais deu-se aos resumos e que as comunicações nunca foram transmitidas. Já os leitores não têm ciência do que é omitido dessas minutas.

\footnotetext{
${ }^{14}$ Nas minutas das sessões cirilianas, vários documentos escritos mencionados nas narrativas das sessões foram incluídos no corpo do texto, uma organização parcialmente preservada nas primeiras traduções, em latim e copta. Nos manuscritos bizantinos, cópias das coleções compiladas a partir do fim da primeira metade do século v, os textos mais longos foram movidos do corpo das minutas e a narrativa alterada convenientemente, incluindo o incipit e indicando que uma cópia estava anexa às minutas.

${ }^{15}$ Veja ACO I 1/2, 79.34-80.29; Allen 2013.

${ }^{16}$ Esses relatos não ressaltam os lógoi portados ou realizados pelos oradores, ante o kairós, nem isolam a linguagem não-verbal do orador em relação à reação da audiência. Em Sipiora 2002, veja sobretudo a Introdução e o ensaio de J.L. Kinneavy.
} 


\section{NARRATIVAS DE UNANIMIDADE}

Os líderes convidados pelo imperador haviam sido instruídos a reunir-se, tal qual em Nicéia e Constantinopla, sob seus augúrios, com apoio de funcionários da administração imperial para gerir os procedimentos, e a sessão devia ser conduzida - talvez até presidida - por Candidiano, comes domesticorum. ${ }^{17}$ Cabia-lhe a abertura da sessão, quando chegassem todos os convidados, pela leitura da carta de Teodósio II, Collectio Vaticana 31 (Collectio Casinensis 23). Nas minutas cirilianas, nada é dito sobre a discussão e a saída ostensiva e simbólica de Candidiano e de um grupo bastante significativo de bispos que optou por não participar de uma sessão que pretendia ser o sínodo imperial sem seguir todas as instruções imperiais. Também saíram os estenógrafos e arquivistas imperiais levando suas anotações e documentos e Candidiano levou consigo a carta Coll. Vat. 31, que lêra com muitas ressalvas, atendendo aos pedidos insistentes dos cirilianos. ${ }^{18} \mathrm{~A}$ descrição ciriliana da sessão começa com um mise en scène dos bispos sentados e uma fala de Pedro, primicerius dos notários de Alexandria, um presbítero. ${ }^{19}$ Pedro lê uma outra carta imperial (a saber, Coll. Vat. 25, endereçada somente a Cirilo) e logo a seguir, Cirilo alude à leitura de uma carta por Candidiano como se fosse mero reforço das instruções anteriores. ${ }^{20}$

Os fatos omitidos da versão ciriliana são conhecidos de uma carta transmitida numa tradução posterior em latim que Candidiano escreveu naquela mesma manhã endereçada aos cirilianos e, de acordo com a rubrica, expôs publicamente em Éfeso. ${ }^{21}$ É entrevisível na obliquidade do discurso nos documentos cirilianos e Orientais, por exemplo, pela menção a Florêncio, co-

${ }_{17}$ ACO I 1/1, 121.14-6.

${ }_{18}$ Graumann 2010a, 10.

${ }_{19}$ ACO I 1/2, 7.34-8.15.

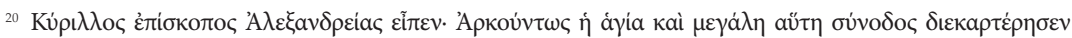

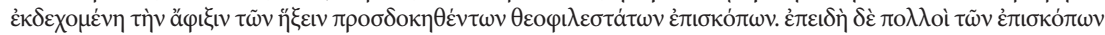

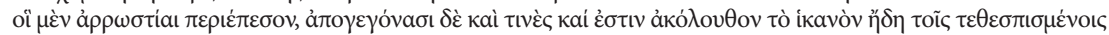

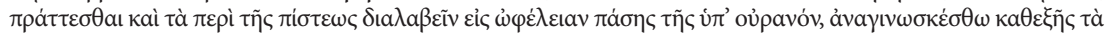

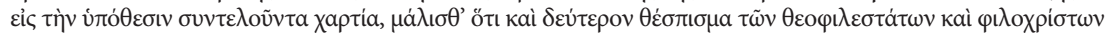

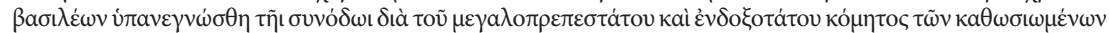

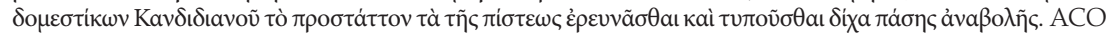
I 1/2, 8.29-9.5.

${ }^{21}$ Collectio Casinensis 84 (ACO I 4, 31-3). Rubrica: Contestatio Candidiam comitis, quam publice, mane audiens synodum celebrari, in Epheso proposuit, ACO I 4, 31.31-2. Leitura da carta: insuper dum uestra reuerentia exigeret sacram domini nostri et piissimi principis, quae directa est ad sanctam synodum, relegi, prius quidem id facere non abnuebam (nec enim dicere refutabo), eo quod non adessent omnes qui ad sanctissimam synodum iussi fuerant conuenire; sed quia uestra religiositas inquit ignorare se quae praecepta sint a domino nostro et optimo principe, necessarium mihi uisum est apparere, ut etiam non praesentibus aliis reuerentissimis episcopis omnibus relegerentur diuinae atque adorabiles literae; ACO I 4, 32.11-17. 
lega de Candidiano, no relato do grupo, que Nestório já fora informado do que ocorrera quando o primeiro grupo enviado pelo sínodo procurou-o, e que os cirilianos sabiam disso..$^{22}$ Contrastam com a brandura alegada pelos cirilianos, as alegações de Nestório e dos bispos que se recusaram a juntar-se ao grupo majoritário, que justificavam a necessidade de tropas pela falta de segurança causada pelas incitações à violência de Memnon e outros contra os assim chamados Orientais. Escreveram isso ao imperador após a sessão ciriliana de 22 de junho, numa carta em que contrapunham sua obediência aos desígnios imperiais à disposição beligerante e facciosa dos "egípcios e asiáticos".23

Pode-se deduzir do conjunto de documentos publicados ou enviados por funcionários e bispos que o status questionável da reunião dos cirilianos tornou-se de imediato conhecido ao menos em Éfeso, e logo na corte de Constantinopla. Nas semanas seguintes, foram enviadas à corte mais cartas e documentos referentes a novos encontros de cada facção, sendo que Candidiano presidiu as sessões dos Orientais quando, como previsto, o grupo que incluía João de Antioquia chegou. Tratava-se, de um lado, de relatos que ignoravam o que punha em cheque seu próprio status, por exemplo, a existência de um outro sínodo, e atribuía o isolamento deliberado de Nestório

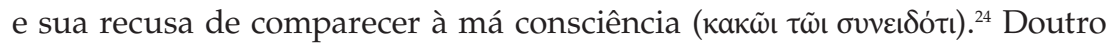
lado, tanto acusações como uma auto-caracterização como minoria acuada e perseguida, perceptível na descrição de agressões cirilianas e de inúme-

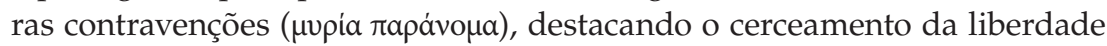
de culto. ${ }^{25} \mathrm{Ou}$ seja, um dos dois discursos apresentava-se consistentemente mais harmonioso na sua seleção de aspectos não-verbais e circunstanciais, embora viesse do grupo que trabalhava desde o início na ilegalidade, sendo esta uma contravenção das leis que não transparece em seus documentos. ${ }^{26}$ É o caso de todas as referências a Candidiano, sempre acompanhadas de fórmulas decorosas tais quais "o mais magnífico e mais glorioso comes dos devotados domestici", ${ }^{27}$ de modo que nas narrativas cirilianas nada leva a

${ }^{22}$ ACO I 1/2, 10.25 .

${ }^{23}$ ACO I 4, 30.23-4.

${ }^{24}$ Carta dos cirilianos ao clero e fiéis de Constantinopla (ACO I 1/2, 70.9-11).

${ }^{25}$ Carta de João de Antióquia a Teodósio II (ACO I 4, 124.31-125.2).

${ }^{26}$ O imperador expressou em Coll. Vat. 83 (ACO I 1/3, 9.31-10.3) e 93 (ACO I 1/3, 31.15-17), por exemplo, que entendia as orientações que exprimira nas sacras de convocação e instrução (exemplificadas por Coll. Vat. 31, ACO I 1/1, 120-1) como imposições legais, logo, seu não cumprimento equivalia a contravenções de leis imperiais, passíveis de represálias, de fato exigidas pelos Orientais (ACO I 1/5, 14.7-13, ACO I 1/5, 124.20-3). Para estudos detalhados dos elementos constitutivos da legislação romana no tempo de Teodósio II, veja Honoré 1998, Harries 1999, Humfress 2007.

${ }^{27}$ Por exemplo, nas minutas da sessão de 22 de junho ocorrem diversas variantes dessa ex-

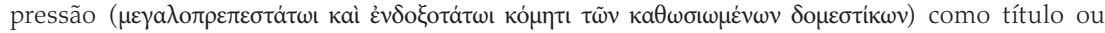
forma de tratamento (ACO I 1/2, 9.4, 10.26). 
crer que sua presença fosse necessária para mais do que a leitura de uma carta imperial, ato mencionado por Cirilo.

\section{RECEPÇÃO DAS NARRATIVAS}

As decisões de nenhum lado foram acatadas pela corte imperial. Por exemplo, os imperadores, na primeira pronúncia a respeito dos eventos sinodais em Éfeso, mencionaram apenas um relato de Candidiano e insistiram que todos se reunissem junto com ele para deliberar e decidir. ${ }^{28}$ Assim, à primeira vista parece que a descrição parcial dos eventos na narrativa da facção majoritária - que é, essencialmente, adotada na historiografia moderna - não foi convincente junto à corte, que execrou as ações

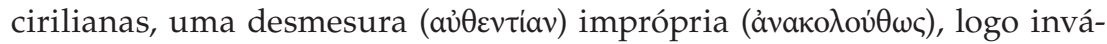
lida (ả $\rho \gamma o u ́ v \tau \omega v) .{ }^{29}$ Por meses, a corte tentou em vão diversas táticas para que as facções se reunissem. Por fim, acatou a renúncia de Nestório e voltou atrás quanto à deposição de Cirilo e Memnon que havia sancionado anteriormente. ${ }^{30}$

Resta portanto conciliar esse demorado processo com relatos antigos que afirmam que o povo de Constantinopla ao receber notícia das decisões sinodais (bem entendido, dos cirilianos) tomou as ruas em celebração e com seus protestos influenciou o imperador a aceitá-las quando as minutas foram lidas publicamente. ${ }^{31}$ A cena como um todo, caracterizada como o sucesso das aclamações de um grupo, motivado pela visão "certa", em promover medidas anti-hereges é típica da literatura hagiográfica. Nela aspectos não-verbais são essenciais na construção de caracteres e da causalidade dos eventos. Também em historiografias e cronografias eclesiásticas eles eram indicativos dos méritos e deméritos pessoais. ${ }^{32}$

As fontes dos relatos são cirilianas. À primeira vista são corroboradas pelas queixas de violência fomentada por rumores espalhados por cirilianos que, entretanto, referem-se a eventos do último quarto de 431, durante a posse de Maximiano. ${ }^{33}$ Visto que agora sabemos que mesmo historiadores eclesiásticos, tais quais Sócrates e Sozomenos, tiveram me-

\footnotetext{
${ }^{28}$ ACO I 1/3, 9-10.

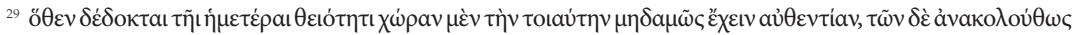

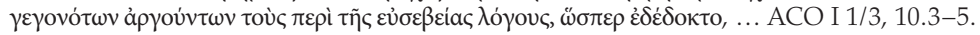

${ }^{30}$ ACO I 1/7, 142.24-33.

${ }^{31}$ Kraatz (1904, 50-5), e a análise das acclamationes em Schwartz (1926, 46-7).

${ }^{32}$ Veja Rapp 2012 e a linha de pesquisa associada a Brown 1988.

${ }^{33}$ ACO I 4, 80.5-7, 16-7, analisado em Frenkel 2014.
} 
nos acesso às minutas como documentos escritos do que se supunha, ${ }^{34}$ resta analisar os relatos antigos das aclamações das minutas e examinar se essas fontes, escritas várias décadas após os acontecimentos, não fundiram os dois momentos críticos, antecipando a agitação relacionada a um evento local para o fim de junho e acrescentando uma leitura pública fictícia de minutas. Pretende-se aqui tão somente averiguar se a leitura das minutas e de documentos nelas inseridos, tal qual descrita nas hagiografias, é plausível.

Por questões técnicas, as minutas que os cirilianos afirmaram anexar à sua carta ao imperador, provavelmente eram apenas uma fração da versão consagrada na tradição conciliar. ${ }^{35}$ Nessa carta, tanto a descrição das convocações ${ }^{36}$ como a reivindicação de não terem demonstrado qualquer hostilidade contra Nestório ${ }^{37}$ ecoavam somente a linguagem verbal e não-verbal das ações e falas dos emissários nos seus relatos contidos nas minutas e não seriam corroboradas pelas comunicações escritas, se já contidas ali.

Junto com as cartas que os cirilianos escreveram quer ao clero, quer aos monges, quer ao povo da capital informando-os da deposição de seu bispo é improvável que foram encaminhadas as minutas. As próprias cartas contêm menos detalhes sobre os procedimentos seguidos do que a carta para a corte Coll. Vat. 81 e o interesse em difundir detalhes sobre os eventos iniciais é limitado. Também a afirmação dos cirilianos na carta para a corte Coll. Vat. 84 de $1^{\circ}$ de julho de que expõem nas atas sua comparação da "pia doutrina" com as declarações de Nestório, comprovadas em seus escritos, sejam esses cartas ou discursos públicos, não corrobora que tais textos já figurassem dentro ou em anexo ao protocolo sinodal de 22 de junho encaminhado ao imperador. ${ }^{38}$

${ }^{34}$ Wallraff 1997, 82, 223-4; Van Nuffelen 2004, 247-64; Graumann 2010b, 147-62.

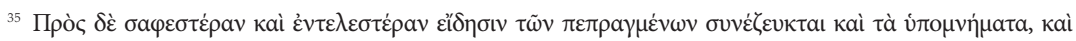

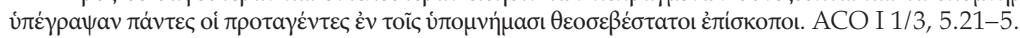

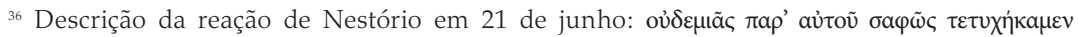

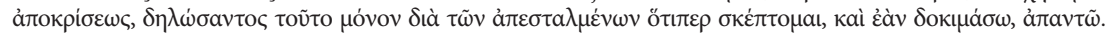

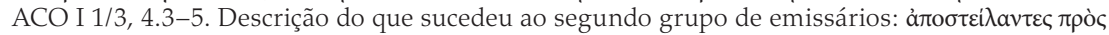

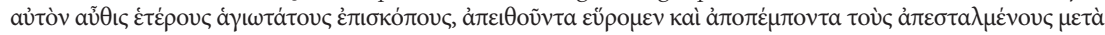

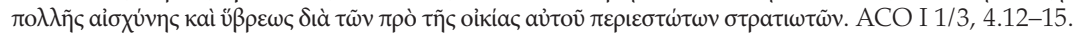

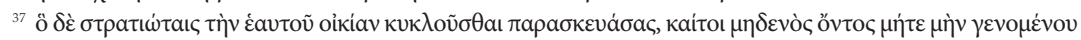

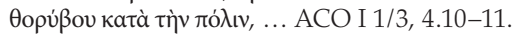

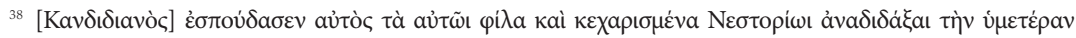

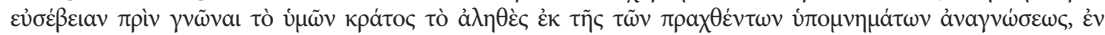

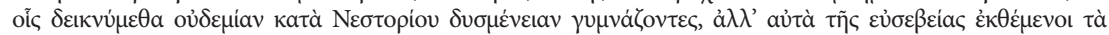

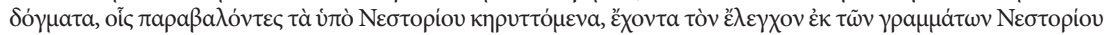

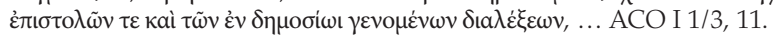




\section{RECONSTRUÇÃO TEXTUAL}

A representação da reação inicial aos eventos conciliares em Éfeso parece menos norteada pela documentação suplementar do que pelos relatos e rumores, tais quais as narrativas nas minutas e as alusões nas cartas, onde predominam a linguagem não-verbal e as circunstâncias. Isso corresponde à construção da verosimilhança pela obliquidade dos discursos amalgamados nas minutas e narrativas, conformes às convenções genéricas de hagiografias e atas sinodais no momento de sua redação. Contudo, a literatura especializada dá pouco realce a esses aspectos em detrimento dos textos que são destacados pela narrativa como comunicações e anexos.$^{39}$ Refletem nisso a caracterização do concílio ciriliano de Éfeso pela construção do discurso autoritativo por meio do aspecto protocolar, preparado para divulgação de um procedimento estruturado ao redor de textos inclusos ou anexados às minutas, difundida já por ocasião do Concílio de Calcedônia. ${ }^{40}$

Essa recepção do sínodo de Éfeso afeta as narrações dos eventos de 431 d.C. A representação típica dos eventos sinodais que se consagrou rapidamente não só no Egito, como também em Constantinopla, e que influenciou a versão encontrada na historiografia tardo-antiga, incorpora a primazia do discurso verbal atestado por excertos ou anexos. Nesse novo contexto é plausível a leitura pública das minutas em Constantinopla. Ela não pode ser corroborada por fontes anteriores, que oferecem uma cronologia e balanço de poder que põe em cheque a correção dos detalhes mencionados nas fontes hagiográficas. Não permitem nem mesmo confirmar que agitação popular ou monástica influenciou a postura do imperador acerca dos eventos conciliares em Éfeso durante junho e julho de 431, outro lugar comum da literatura do quinto e sexto séculos.

\footnotetext{
${ }^{39}$ Os incipientes estudos de gesticulação e aclamação tardo-antigas lidam, quando muito, com alguns exemplos de aclamações durante sessões sinodais e não há ainda estudos de cenas tais quais relatadas pelos emissários que ora estudamos. Veja Aldrete 1999, 129-47; Wiemer 2004, 36-44.

${ }^{40}$ Atribui-se amiúde ao concílio ciriliano a criação de um procedimento centrado em evidência textual que resulta numa concepção de acta conciliorum em que todo o seu conteúdo e não só os decretos é imbuído de autoridade canônica. Veja Price 2009, 322-3. A originalidade de Éfeso I pode ser matizada pelos poucos exemplos remanescentes de protocolos anteriores e sobretudo pelo contexto legal e jurídico tardo-antigo: veja De Halleux 1993, 50-1; Graumann 2002, 385-98; Graumann 2009.
} 


\section{CONCLUSÃO}

Em suma, pelo exame em textos de atas sinodais e de hagiografias da linguagem escrita e oral e dos elementos da actio e do contexto, contidos nos discursos oblíquos que ali se sobrepõe, obteve-se uma representação matizada de debates sinodais do século v. No caso das convocações de Nestório, conclui-se que o conteúdo das comunicações escritas, às quais é dado realce na literatura medieval, moderna e contemporânea, teve influência reduzida nos eventos e na reação imediata aos encontros cirilianos. Como documentos escritos foram importantes na construção da representatividade dos emissários, refletindo a profícua tensão entre oralidade e literatura na Antiguidade Tardia, que embasa a própria autoridade das minutas. São as declarações dos emissários e os elementos das circunstâncias e da reação de cirilianos, Orientais e militares que dominam os relatos nas minutas e cartas e aos quais se faz referências nas epístulas e narrativas. Resulta uma representação parcial dos eventos que tem função argumentativa, de modo que a descrição à primeira vista detalhada de um evento, caracterizado como típico e tradicional, não é representativo de um amplo fenômeno literário, mas como o próprio acontecimento, é polêmico. A narrativa ciriliana fazia parte da representação de consenso, apoiada por documentos escritos, proposta pelas minutas e cartas, mas a comunicação escrita e a descrição da comunicação oral ali contidos continuam em tensão que enfraquece o consenso proposto.

\section{REFERÊNCIAS}

Aldrete, G. S. 1999. Gestures and acclamations in ancient Rome. Baltimore: Johns Hopkins University Press.

Allen, P. 2013. "Prolegomena to a study of the letter-bearer in Christian antiquity." Studia Patristica 62:481-92.

Brown, P. 2008. The body and society: men, women, and sexual renunciation in early Christianity. New York; Chichester: Columbia University Press.

Chrysos, E. 1983. "Konzilsakten und Konzilsprotokolle vom 4. bis 7. Jahrhundert." Annuarium Historiae Conciliorum 15(1):30-40.

Cubitt, C. 2009. "The Lateran Council of 649 as an ecumenical council." In Chalcedon in context: church councils 400-700, edited by R. Price and M. Whitby, 133-47. Liverpool: Liverpool University Press. (Translated texts for historians, Contexts 1).

Fraisse-Coué, C. 1995. "Le débat théologique au temps de Théodose II: Nestorius." In Histoire du christianisme des origines à nos jours, 2: Naissance d'une chrétienté (250-430), édité par C. Pietri, L. Pietri et J. Biarne, 499-550. Paris: Desclée. 
Frenkel, L. M. 2014. “'Dear prefect, Stop the ill rumour!' - John of Antioch's tactics to counter Cyrillian propaganda after the Council of Ephesus I." Studia Patristica $72: 257-68$.

Graumann, T. 2009. "'Reading' the First Council of Ephesus (431)." In Chalcedon in context: church councils 400-700, edited by R. Price and M. Whitby, 27-44. Liverpool: Liverpool University Press. (Translated texts for historians, Contexts 1).

Graumann, T. 2010a. "Protokollierung, Aktenerstellung und Dokumentation am Beispiel des Konzils von Ephesus (431)." Annuarium Historiae Conciliorum 42(1):7-34.

Graumann, T. 2010b. "Towards the reception of the Council of Ephesus (431): public sentiment and early theological responses." Studia patristica 45:147-62.

Harries, J. 1999. Law and empire in late antiquity. Cambridge, UK: Cambridge University Press.

Hatlie, P. 2007. The monks and monasteries of Constantinople, ca. 350-850. Cambridge: Cambridge University Press.

Honoré, T. 1998. Law in the crisis of empire, 379-455 AD: the Theodosian dynasty and its quaestors with a palingenesia of laws of the dynasty. Oxford: Clarendon Press.

Humfress, C. 2007. Orthodoxy and the courts in late antiquity. Oxford: Oxford University Press.

Kraatz, W. 1904. Koptische Akten zum ephesinischen Konzil vom Jahre 431. Leipzig: J.C. Hinrichs. (Texte und Untersuchungen zur Geschichte der altchristlichen Literatur, Band 26, Heft 2).

Leppin, H. 2003. "The church historians (I): Socrates, Sozomenus, and Theodoretus." In Greek and Roman historiography in late antiquity: fourth to sixth century A.D., edited by G. Marasco, 219-54. Leiden: Brill.

Millar, F. 2006. A Greek Roman Empire: power and belief under Theodosius II (408/450). Berkeley: University of California Press. (Sather Classical Lectures, v. 64).

Nuffelen, P. V. 2004. Un héritage de paix et de piété: étude sur les histoires ecclésiastiques de Socrate et de Sozomène. Leuven: Peeters. (Orientalia Lovaniensia analecta, 142).

Price, R. 2009a. "Truth, omission, and fiction in the Acts of Chalcedon." In Chalcedon in context: church councils 400-700, edited by R. Price and M. Whitby, 92-106. Liverpool: Liverpool University Press. (Translated texts for historians, Contexts 1).

Price, R. 2009b. "The Development of a Chalcedonian Identity in Byzantium (451553)." Church History and Religious Culture 89(1-3):307-25.

Rapp, C. 2012. "Hagiography and the cult of saints in the light of epigraphy and acclamations." In Byzantine religious culture: studies in honor of Alice-Mary Talbot, edited by Alice-Mary M. Talbot, Denis Sullivan, Elizabeth A. Fisher and Stratis Papaioannou, 291-312. Leiden: Brill. (Medieval Mediterranean, 92).

Schwartz, E., ed. 1914ff. Acta conciliorum oecumenicorum. Iussu atque mandato Societatis Scientiarum argentoratensis edidit Eduardus Schwartz [continuauit Johannes Straub]. Berlin: Walter de Gruyter.

Schwartz, E. 1926. Cyrill und der Mönch Viktor. Wien/Leipzig: Hölder-Pichler-Tempsky. (Sitzungsberichte - Akademie der Wissenschaften in Wien. PhilosophischHistorische Klasse, 208. Bd., 4. Abh.).

Sipiora, P., and J. S. Baumlin, ed. 2002. Rhetoric and kairos: essays in history, theory, and praxis. Albany, NY: State University of New York Press. 
Van Uytfanghe, M. 1993. "L'hagiographie: un 'genre' chrétien ou antique tardif?" Analecta Bollandiana 111:135-88.

Wallraff, M. 1997. Der Kirchenhistoriker Sokrates: Untersuchungen zu Geschichtsdarstellung, Methode und Person. Göttingen: Vandenhoeck \& Ruprecht. (Forschungen zur Kirchen- und Dogmengeschichte, 68).

Weckwerth, A. 2010. Ablauf, Organisation und Selbstverständnis westlicher antiker Synoden im Spiegel ihrer Akten. Münster: Aschendorff. (Jahrbuch für Antike und Christentum. Ergänzungsband, Kleine Reihe, 5).

\section{*}

Title. Unanimity and dialogue: argumentative purpose of late-antique synodical proceedings and hagiographies.

Abstract. I analyse summonses mentioned in letters and proceedings circulated by the majoritarian faction of the Christian leaders gathered in Ephesus in A.D. 431, highlighting its layers of meaning and the aspects of verbal and non-verbal communication to which they refer. I contrast them with the mutual accusations and sanctions, mentioned in letters and pamphlets by imperial officials and faction leaders, which corroborate or weaken the representation of consensus by means of written documents. Thus, I problematise the narrative which purports to meet the imperial injunctions of discussions about religious issues relying on the pattern set at Nicaea, performed in unanimity and dialogue, and secured imperial endorsement of the decisions. This literary and historical analysis of the argumentative purpose of late-antique synodical proceedings corroborates that also in the more extensively documented meetings of ecclesiastic leaders, the representation of the events remains partial, and they cannot be taken as typical representatives of a wider phenomenon. Analysing the reliability of the reports of popular and monastic demonstrations in Constantinople, especially the references to non-verbal communication, contributes to the study of the early circulation of synodical acts.

Keywords. Orality; late-antique oratory; epistolography; spread of synodical proceedings; Roman imperial administration. 